\title{
Riscos ocupacionais a que os trabalhadores da enfermagem referem estar expostos em central de material estéril
}

\author{
Henrique Eduardo Alves ${ }^{l}$; Cecília Nogueira Valença ${ }^{1}$; Dimitri Taurino Guedes ${ }^{l}$; Aline Cristine do Rego Reis ${ }^{2}$; \\ Juliana de Freitas Vasconcelos Sugette ${ }^{3}$; Symara Abrantes Albuquerque de Oliveira Cabral ${ }^{5}$
}

Resumo: Objetivo: Identificar os riscos ocupacionais a que os profissionais de enfermagem referem estar expostos. Método: Trata-se de uma pesquisa exploratória, qualitativa, realizada junto à equipe de enfermagem da central de material estéril (CME) no Hospital Universitário Ana Bezerra e no Hospital Regional Aluízio Bezerra, em Santa Cruz/RN. Os participantes foram entrevistados, tendo suas respostas gravadas, transcritas e analisadas de acordo com a análise de conteúdo temática. Resultados: Os trabalhadores de enfermagem na CME precisam utilizar medidas de controle para esses riscos, tais como os equipamentos de proteção individual adequados e ambiente seguro. Com base nas respostas dos participantes, foi identificado que não houve dimensionamento de recursos humanos para as atividades, falta de fornecimento de EPIs adequados, proporcionando grandes riscos à saúde dos profissionais. Conclusão: Os riscos ocupacionais presentes na CME geralmente compreendem: os riscos biológico, ergonômico, físico, de acidentes e químico, que poderão causar a danos à saúde dos profissionais de enfermagem que atuam presentes na CME.

Palavras-Chave: enfermagem; riscos ocupacionais; saúde do trabalhador.

\section{Occupational risks to which the nursing workers report being exposed in the central sterile equipment}

\begin{abstract}
Objective:Identify the occupational risks to which nursing professionals report being exposed. Method: This is an exploratory research, qualitative, conducted by the nursing staff of the central sterile equipment (CME) at the University Hospital Ana Bezerra and the Regional Hospital Aluízio Bezerra, Santa Cruz/RN. Participants were interviewed, and their responses recorded, transcribed and analyzed according to thematic content analysis. Results: The nursing staff in CME must use control measures for these risks, such as personal protective equipment suitable and safe environment. Based on the responses of the participants, it was identified that there was no scaling of human resources for the activities, failure to provide adequate PPE, providing great health risks to workers. Conclusion: Occupational hazards present in CME generally comprise: the biological, ergonomic, physical, chemical accidents and risks that may cause harm to the health of nursing professionals working attending the CME.
\end{abstract}

Keywords: nursing, occupational hazards, occupational health.

\footnotetext{
${ }^{1}$ Faculdade de Ciências da Saúde do Trairí, FACISA. Universidade Federal do Rio Grande do Norte, UFRN. Santa Cruz, RN.

${ }^{2}$ Hospital Universitário Ana Bezerra. Santa Cruz, RN.

${ }^{3}$ Graduação em Medicina pela Universidade Federal do Ceará (2015), atualmente residente do segundo ano de Clínica Médica do Hospital Universitário Walter Cantídio. No momento, trabalha na uti adulto do Hospital Universitário Walter Cantídio, uti adulto do Hospital Antônio Prudente, médico do setor de emergência do Hospital Geral de Fortaleza e time de resposta rápida (TRR) do Hospital do Coração de Messejana. Contato: julianafv@ hotmail.com.

${ }^{5}$ Doutoranda em Ciências da Saúde - Faculdade de Ciências Médicas da Santa Casa de São Paulo, Brasil. Contato: symara_abrantes@hotmail.com;
} 


\section{Introdução}

Os trabalhadores que exercem suas atividades na central de material estéril (CME) têm o compromisso na defesa contra inúmeras doenças do âmbito hospitalar, com o intuito de diminuir microorganismos que estão inseridos nos instrumentos e insumos dos profissionais de saúde (PEZZI; LEITE, 2010).

A CME conta com a preconização de ações desempenhando o processo de artigos para a vitalidade e prevenções (BRASIL, 2012). Os riscos ocupacionais presentes na CME são: biológico, ergonômico, físico, mecânico ou de acidentes e químico.

O risco biológico está relacionado a vírus, bactérias e protozoário, fungos e bacilos e parasitas. $\mathrm{O}$ ergonômico envolve má postura na execução de suas atividades repetitivas e monótonas, problemas ergonômicos. O físico se relaciona a ruídos, vibrações, calor, radiações ionizantes, radiações não-ionizantes, umidade e frio (BRASIL, 2014).

O risco de acidentes decorre do ambiente físico e do processo de trabalho e condições tecnológicas, impróprias, capazes de provocar lesões à integridade física do trabalhador. $\mathrm{O}$ químico está relacionado a substâncias químicas que se encontram nas formas líquida, sólida e gasosa. Quando absorvidas pelo organismo, podem produzir reações tóxicas e danos à saúde (BRASIL, 2014).

Segundo Ribeiro e Vianna (2012), os riscos ocupacionais na CME podem estar relacionados o uso inadequado de Equipamentos de Proteção Individual (EPIs), pois o profissional poderá estar exposto aos seguintes riscos ocupacionais: contaminação por respingos de sangue pelo manuseio de artigos, secreções corpóreas, e acidentes percutâneos.

Os equipamentos de proteção individual (EPIs) quanto os equipamentos de proteção coletiva propiciam condições para a proteção pessoal e coletiva com a função de viabilizar a prevenção de riscos de contaminação com material biológico e demais riscos ocupacionais (CAMARA et al., 2011).

Sabe-se da importância do enfermeiro na atuação da CME. Nesse setor é notória a necessidade das rotinas, que são estabelecidas por esse profissional. Além disso, promove um trabalho qualificado com eficiência nos serviços de esterilização, promove meios de 
segurança, o que impede infecções cruzadas no âmbito hospitalar (OURIQUES; MACHADO, 2013).

Tendo em vista a importância da equipe de enfermagem no reestabelecimento da saúde do paciente, além do risco potencial de contaminação paciente/profissional, Valença et al. (2013) afirmam que é possível compreender que os trabalhadores de enfermagem estarão expostos a determinados riscos e doenças ocupacionais, comprometendo não somente a qualidade da assistência prestada por esses profissionais, quanto sua própria qualidade de vida, sendo inevitável se fazer prática constante do uso de EPIs por toda a equipe, além de obter meios que possibilite alternativas para eliminação dos agravos.

$\mathrm{Na}$ área física da CME, os profissionais têm a função de promover a desinfecção; direcionar os materiais; fazer a higienização dos produtos; receber as peças de vestimentas do setor da lavagem de roupas; Favorecer a esterilização dos aparelhos e roupas, com processo físicos e químicos; Promover a segurança mediante a meios que possibilitem o controle biológico; Definir as datas dos instrumentos e roupas esterilizados; por fim, direcionar os produtos para os setores de acordo com sua necessidade (SOCIEDADE BRASILEIRA DE ENFERMEIROS DE CENTRO CIRÚRGICO, RECUPERAÇÃO ANESTÉSICA E CENTRAL DE MATERIAL E ESTERILIZAÇÃO, 2009).

A relevância da CME para uma instituição é indiscutível para a execução das atividades de limpeza, desinfecção e esterilização adequadas dos materiais. Como em outros setores do hospital, a CME também incorporou, nos dias atuais, a presença da tecnologia, inovando nos processos de desinfecção e esterilização dos materiais, equipamentos e insumos em tempos mínimos.

As características de trabalho do CME são distintas de outras unidades do hospital. Apesar das normativas legais sobre a estruturação adequada da CME, geralmente não são atendidos os requisitos de funcionamento de estrutura física e de atividades realizadas, impactando nas atividades dos profissionais desta unidade (GIL; CAMELO; LAUS, 2013).

Diante do impacto das atividades laborais na CME na saúde dos trabalhadores deste setor, sobretudo de enfermagem, compreende-se que eles estão expostos a graves riscos ocupacionais e precisam utilizar medidas de proteção e controle para esses riscos, tais como os EPIs adequados e meios que possibilite a eliminação de agravos que acomete a saúde dos profissionais, além de uma gestão que vise à segurança desses profissionais. 
Esta investigação teve como objetivo identificar os riscos ocupacionais a que os profissionais de enfermagem referem estar expostos em ambiente hospitalar.

\section{Métodos}

A pesquisa caracteriza-se como exploratória, de abordagem qualitativa. Esta investigação foi realizada no setor de CME do Hospital Universitário Ana Bezerra (HUAB) e Hospital Regional Aluízio Bezerra (HRAB), ambos os hospitais são localizados na cidade de Santa Cruz-RN.

Os participantes foram profissionais da equipe de enfermagem que atuam na CME no HUAB e no HRAB. Do total de 24 profissionais presentes no setor, participaram 17 entrevistados. Como critério de inclusão no estudo, foi coletado o profissional de enfermagem do HUAB e HRAB que trabalha há pelo menos três meses no setor da CME. Foram excluídos desta pesquisa os profissionais que não estiveram presentes no setor durante o período de coleta de dados ou os que se recusaram a participar do estudo.

O projeto de pesquisa foi aprovado pelo CAAE $n^{\circ} 44892415.1 .0000 .5568$ do Comitê de Ética, da Faculdade de Ciências da Saúde do Trairí. Todos os participantes assinaram o Termo de Consentimento Esclarecido, a coleta foi durante o mês de julho de 2015.

Para a obtenção dos dados para a pesquisa foi utilizado um roteiro de entrevista semiestruturado, com questões abertas sobre EPIs e os riscos ocupacionais que a equipe de enfermagem refere estar presentes na CME. A entrevista aos profissionais foi aplicada durante seu horário de trabalho.

As falas dos participantes foram gravadas, transcritas e analisadas de acordo com a técnica de análise de conteúdo temática, segundo Deslandes, Gomes e Minayo (2010).

Além disso, o direcionamento da análise de conteúdo da temática foi através das obras pesquisadas, correlacionando com as análises do conteúdo em estudo, seguindo as etapas de Pré-análise; exploração do material e tratamentos dos resultados/ Interferência/Interpretação (DESLANDES; GOMES; MINAYO, 2010). 
Os entrevistados receberam a denominação de Tec (técnico de enfermagem) e Enf (enfermeiro) de modo a não serem identificados e foram numerados de acordo com a sequência da coleta de dados realizada.

\section{Resultados e discussão}

$\mathrm{Na}$ CME podem ser encontrados diversos riscos ocupacionais, como: risco físico, químico, biológico, ergonômico e mecânico ou de acidentes. O quadro abaixo mostra os riscos ocupacionais a que os profissionais da CME dos hospitais de Santa Cruz/RN estão submetidos de acordo com a percepção dos trabalhadores.

Quadro 1 Riscos ocupacionais e seus fatores no trabalho dos profissionais de enfermagem da CME.

\begin{tabular}{|l|l|}
\hline Risco & Fator \\
\hline Físico & Ruído, calor, umidade e vibrações. \\
\hline Químico & Poeiras, gases e vapores. \\
\hline Biológico & Vírus, bactérias, fungos e insetos. \\
\hline Ergonômico & $\begin{array}{l}\text { Levantamento e transporte de peso, monotonia, posturas } \\
\text { inadequadas de trabalho. Trabalho em turnos. }\end{array}$ \\
\hline $\begin{array}{l}\text { Risco Mecânico ou de } \\
\text { Acidentes }\end{array}$ & $\begin{array}{l}\text { Arranjo físico inadequado, iluminação inadequada, máquinas e } \\
\text { equipamentos sem proteção. }\end{array}$ \\
\hline
\end{tabular}

Fonte: dados da pesquisa, 2015.

Pelos relatos obtidos em ambos os hospitais, não há um espaço no setor adequado para as atividades laborais na CME com segurança.

Acho que o principal é problema do ambiente é que ele é pequeno. O espaço é muito limitado. Às vezes a gente está fazendo algum procedimento, e ocorrem respingos da solução de material orgânico. Acho que esse é o maior problema: espaço. (Tec 08).

É o desconforto que a gente sente, está baseado mais ergonomicamente, né? Na ergonomia do serviço, geralmente a gente fica muito em pé. Às vezes fica é muito sentado e não tem uma posição confortável. (Tec 03).

Lá é muito quente, então, eu acredito que se tivesse mais ar condicionado poderia trazer um conforto maior para os funcionários. (Enf 09). 
A partir de instalação de aparelhos que viabilizem um setor climatizado expresso pelo Enf 9, a instituição poderá fornecer um melhor bem estar dos trabalhadores. Uma mudança do arranjo físico, com infraestrutura recomendada pelo Ministério da Saúde, também pode propiciar assim a comodidade dos trabalhadores.

Segundo Espindola e Fontana (2012), reforçam o comentário anterior defendendo a ideia que os funcionários contentes desenvolvem o trabalho com precaução, aceitação, amabilidade, o que pode proporcionar um ambiente harmonioso, sem estresse com os profissionais do ambiente e dos demais setores. Jamais pode ocorrer falta de cuidado no ambiente.

É também um problema o próprio setor que você está vendo! A divisão aqui é uma janela do expurgo para sala de pré parto. O próprio setor não é adequado para manusear os equipamentos. Deveria ter uma equipe e tem dia que só funciona com um auxiliar. (Tec 01)

Pessoas para trabalhar? Tem poucas aqui. Tem dia que só tem uma para um setor todinho e não tem nem como dividir uma para o expurgo e outra para a separação de material estéril em outro canto. Fica a mesma pessoa fazendo tudo (Tec 02).

Além do arranjo físico inadequado, o Tec 1 discutiu sobre o dimensionamento da equipe. É essencial que cada instituição possa promover o cálculo para a unidade especial de acordo com a resolução do COFEN de $n^{\circ}$ 293/2004 sobre o dimensionamento de profissionais que atuam no setor da CME (CONSELHO FEDERAL DE ENFERMAGEM, 2004), de modo a garantir que a equipe de enfermagem possa desenvolver suas atividades de forma segura e sem sobrecarga ou aumento do ritmo de trabalho por acúmulo de funções.

Pode-se ressaltar a dimensão dos danos aos fatores financeiros e ao trabalho acometendo a entidade e os funcionários da enfermagem, sobretudo, pela ausência dos funcionários e a presença de problemas assim como agravos, comprendendo os riscos biológicos, físicos, de acidentes, químicos e ergonômicos, prejudicando e propiciando aos danos em atividades laborais (DUARTE; MAURO, 2010).

Dessa forma é evidenciado que não há uma atenção aos indivíduos dos setores da CME para um dimensionamento que impeça ou diminua os riscos ocupacionais como exposição aos fluidos corpóreos, acidentes com materiais perfurocortantes, além do desgaste físico e psicológico pela sobrecarga de trabalho. 
Em algumas falas foi possível observar o incômodo dos profissionais, com a falta de espaço, os dados da RDC n . 307/2002 indicam com precisão as dimensões adequadas para a construção de uma CME segura.

Quadro 2 Área física da CME: ambientes e dimensões.

\begin{tabular}{|c|c|}
\hline AMBIENTE & DIMENSÃO MÍNIMA \\
\hline $\begin{array}{l}\text { Sala composta de: Área para recepção, } \\
\text { descontaminação e separação de materiais. }\end{array}$ & \multirow[t]{2}{*}{$\begin{array}{l}\text { 0,08 } \mathrm{m}^{2} \text { por leito com área mínima } \\
\text { de } 8,0 \mathrm{~m}^{2}\end{array}$} \\
\hline Área para lavagem de materiais. & \\
\hline Sala composta de: Área para recepção de roupa limpa. & $4,0 \mathrm{~m}^{2}$ \\
\hline Área para preparo de materiais e roupa limpa. & $\begin{array}{l}0,25 \mathrm{~m}^{2} \text { por leito com área mínima } \\
\text { de } 12,0 \mathrm{~m}^{2}\end{array}$ \\
\hline $\begin{array}{l}\text { Área para esterilização física; Área para esterilização } \\
\text { química líquida. }\end{array}$ & $\begin{array}{l}\text { A depender de equipamento } \\
\text { utilizado. Distância mínima entre as } \\
\text { autoclaves }>20 \mathrm{~cm}\end{array}$ \\
\hline $\begin{array}{l}\text { Sala de armazenamento e distribuição de materiais e } \\
\text { roupas esterilizados. }\end{array}$ & $\begin{array}{l}0,2 \mathrm{~m}^{2} \text { por leito com mínimo de } \\
10,0 \mathrm{~m}^{2}\end{array}$ \\
\hline $\begin{array}{l}\text { Área para armazenagem e distribuição de materiais } \\
\text { esterilizado e descartáveis. }\end{array}$ & $\begin{array}{l}25 \% \text { da área de armazenagem de } \\
\text { material esterilizado. }\end{array}$ \\
\hline
\end{tabular}

Fonte: RDC nº 307/2002, Ministério da Saúde.

A área física da CME é obrigada a conceder a organização do curso consecutivo de uma corrente de itens no ambiente da instituição, impedindo o funcionário requisitado em direção ao setor infectado para a área limpa, dessa forma proporcionando um fluxo adequado. (SOCIEDADE BRASILEIRA DE ENFERMEIROS DE CENTRO CIRÚRGICO, RECUPERAÇÃO ANESTÉSICA E CENTRAL DE MATERIAL E ESTERILIZAÇÃO, 2009).

Na CME é evidenciado o fluxo unidirecional de forma, assim como: Expurgo respectivo a área suja, o preparo de material e carga de autoclave à área limpa, além da retirada de material da autoclave e guarda do material estéril correspondendo a área de estéril (SOCIEDADE BRASILEIRA DE ENFERMEIROS DE CENTRO CIRÚRGICO, RECUPERAÇÃO ANESTÉSICA E CENTRAL DE MATERIAL E ESTERILIZAÇÃO 2009).

Levando em consideração o uso dos EPIs na proteção do profissional da saúde, Penna (2010) aborda a biossegurança como o conjunto de ações que visam à prevenção, 
minimização e/ou a eliminação de riscos que possam comprometer a saúde humana ou a qualidade de vida dos trabalhadores. Envolve a análise dos riscos que os indivíduos estão expostos no ambiente de trabalho, englobando vários aspectos.

Segundo a Norma Regulamentadora 6, de 2001, "considera-se Equipamento de Proteção Individual - EPI, todo dispositivo ou produto, de uso individual utilizado pelo trabalhador, destinado à proteção de riscos suscetíveis de ameaçar a segurança e a saúde no trabalho" (BRASIL, 2001). Essa norma deve ser implementada e fornecida os EPIs pelos responsáveis da gerência da instituição para os trabalhadores, com o intuito de serem utilizados de forma correta.

Os EPIs utilizados na CME são: gorro, óculos, máscara, luvas grossas de borracha, avental impermeável e sapato fechado, propiciando no setor a redução de riscos com acidentes ocupacionais (RIBEIRO; VIANNA, 2010).

Faltam equipamentos de proteção individual importantes para a CME, entre eles, óculos de proteção, além disso, luvas de cano longo, avental máscara de carvão ativado e protetores auriculares, que foram mencionados pelos entrevistados dessas instituições.

\footnotetext{
Eu acho que todos os equipamentos que citei são descartáveis. E existe equipamento de proteção que não é descartável, como as luvas, uma máscara apropriada, que a gente só fez conhecer, avental que a gente não usa. (Tec 01).

Eu sinto falta principalmente dos óculos, porque a gente às vezes coloca o material no produto e respinga nos olhos. Principalmente os óculos. (Tec 04).

Eu acho que deveria ter o protetor auricular porque as autoclaves fazem muito barulho, e também a máscara de carvão ativado necessários nos expurgos, porque têm muito produtos que têm odores fortes e são tóxicos para a gente (Enf 10). Falta a luva de cano longo. (Tec 07).
}

Os profissionais de enfermagem que atuam neste setor estão expostos a acidentes com materiais perfuro-cortantes contaminados. Diante desta problemática, destaca-se a importância da supervisão do enfermeiro, na observação, na checagem de materiais e na realização de capacitações acerca do uso adequado de EPIs pela equipe de enfermagem. Neste sentido, pode-se observar que o risco biológico foi enfatizado:

[Os riscos] são vários, porque a gente entra muito em contato com matéria orgânica, material biológico. Entra em contato com bactéria, vírus. Então a gente tem muito contato, tem muita chance de pegar hepatite B, HIV ou alguma bactéria que esteja em algum objeto contaminado (Enf 10). 
A infecção por hepatite B é uma doença ocupacional relevante no ambiente de saúde e os profissionais de Enfermagem estão susceptíveis a adquiri-la, se medidas de precaução, tanto coletivas quanto individuais, não forem implementadas (ARAÚJO; SILVA, 2014, p.181).

Eu acho que falando no geral existe a autoconfiança dos profissionais. Eles muitas vezes não usam os equipamentos de proteção individual por acharem que têm muito tempo de experiência. Então eles se acham autosuficientes, entendeu? Independente do setor o risco é esse: eles acharem que não precisam, que não é necessário usar os equipamentos no geral (Enf 15).

Apesar de toda a importância epidemiológica, ainda persiste um grau significante de falta de informações ou banalização dos agravos causados pela contaminação dos vírus HIV, Hepatite B e C, entre profissionais da saúde. Mesmo com o uso de EPI ainda ocorre inúmeros acidentes, seja pela falta de EPI, ou pela escassez de treinamentos e de recursos humanos especializados nesses setores críticos, como a CME (SILVA et al., 2010).

Quase todos os funcionários que representam a categoria de enfermagem são vulneráveis a inúmeras situações que induzem a acidentes com materiais infectados. Dessa forma, é preciso desenvolver pesquisas que identifiquem o surgimento desses acontecimentos que proporcionam acidentes com esses profissionais (DANIEL, 2011).

Existe o risco de se contaminar pela falta de utilização do EPI. A participante reforça a ideia de que os profissionais se sentem acomodados pela rotina. Dessa forma, evitam a utilização do EPI, embora possam surgir acidentes e doenças ocupacionais, propiciando consequências permanentes na vida desses profissionais.

\section{Considerações Finais}

O estudo identificou os principais riscos ocupacionais na CME de natureza química, física, ergonômica, biológica ou mecânica, os quais interferem na saúde dos profissionais de enfermagem que atuam neste setor, gerando consequências que poderiam ser evitadas.

As opiniões dos profissionais foram evidenciadas pelos riscos ocupacionais presentes no ambiente da execução das atividades laborais, estando correlacionado com problemas que 
solidifica as afirmações desses servidores constatado por uma má condição de trabalho, sobrecarga, falta de dimensionamento de indivíduos, espaço insuficiente, ausência de EPIs recomendados, viabilizando eventuais acidentes com riscos de contaminação, além de problemas de ergonomia, biológicos e químicos.

É importante ressaltar uma prevenção com base nas medidas de biossegurança, através de ações importantes para que possa construir uma cultura de segurança nos diversos setores do âmbito hospitalar de acordo com os protocolos fornecidos pela gestão da instituição, sempre com ação conjunta do enfermeiro.

\section{Referências}

ARAÚJO, T. M. E.; SILVA, N.C. Acidentes perfurocortantes e medidas preventivas para hepatite B adotadas por profissionais de enfermagem nos serviços de urgência e emergência de Teresina Piauí. Revista Brasileira de Saúde Ocupacional, v. 39, n.130, p. 175-183, 2014. Disponível em:< http://www.scielo.br/scielo.php?pid=S030376572014000200175\&script=sci_arttext>. Acesso: 23 de ago de 2015.

BRASIL. RDC n.15. Dispõe sobre requisitos de boas práticas para o processamento de produtos para saúde e dá outras providências. Brasília/DF, 2012.

BRASIL. Norma Regulamentadora 6. Dispõe sobre segurança e medicina do trabalho. Brasília/DF, 2001

BRASIL. Norma Regulamentadora 9. Estabelece a obrigatoriedade da elaboração e implementação, por parte de todos os empregadores e instituições que admitam trabalhadores como empregados, do Programa de Prevenção de Riscos Ambientais. Brasília/DF, 2014.

CÂMARA, P.F. et al. Investigação de acidentes biológicos entre profissionais da equipe multidisciplinar de um hospital. Revista de enfermagem da UERJ. v.19 n.4, p. 583-586, 2011. Disponível em:<http://www.facenf.uerj.br/v19n4/v19n4a13.pdf >. Acesso: 23 de ago de 2015.

CONSELHO FEDERAL DE ENFERMAGEM. Resolução $n^{o}$ 293/2004, 21 de setembro de 2004. Fixa e estabelece parâmetros para o Dimensionamento do Quadro de Profissionais de Enfermagem nas Unidades Assistenciais das Instituições de Saúde e Assemelhados. Rio de Janeiro, 2004.

DANIEL, K.C. Riscos ocupacionais durante a higienização de materiais em uma central de material de esterilização. 2011. 34 f. Trabalho de conclusão de curso (Monografia) Universidade Federal do Rio grande do Sul. 2011. Porto Alegre , RS, 2011. Disponível em: 
<https://www.lume.ufrgs.br/bitstream/handle/10183/37532/000822608.pdf? sequence=1 > . Acesso: 29 de julho de 2015.

DESLANDES, S.F.; GOMES, R.; MINAYO, M. C. S. (org.). Pesquisa social: teoria, método e criatividade. 29. ed. Petrópolis, RJ: Vozes, 2010.

DUARTE, N.S.; MAURO, M.Y.C. Análise dos fatores de riscos ocupacionais do trabalho de enfermagem sob a ótica dos enfermeiros. Revista brasileira de saúde ocupacional. v.35, n.121, p. 157-167, $2010 . \quad$ Disponível em: $<$ http://www.redalyc.org/articulo.oa?id=100513733017>. Acesso em 30 de julho de 2015.

ESPINDOLA, M.C.G.; FONTANA, R.T. Riscos ocupacionais e mecanismos de autocuidado do trabalhador de um centro de material e esterilização. Revista Gaúcha de Enfermagem. v.33, n.1, p.116-123, 2012. Disponível em: http://www.scielo.br/pdf/rgenf/v33n1/a16v33n1.pdf >. Acesso em 30 de julho de 2015.

GIL, R.F.; CAMELO, S.H.; LAUS, A.M. Atividades do enfermeiro de Centro de Material e Esterilização em instituições hospitalares. Texto contexto - enfermagem. v.22, n.4, p. 927934, 2013. Disponível em:<http://www.scielo.br/scielo.php?pid=S010407072013000400008\&script=sci_arttext $>$. Acesso: 09 de dez de 2014.

OURIQUES, C.M.; MACHADO, M.E. Enfermagem no processo de esterilização de materiais. Texto contexto - enfermagem. v.22, n.3, p.695-703, 2013. Disponível em: <http://www.scielo.br/pdf/tce/v22n3/v22n3a16.pdf >. Acesso: 05 fev 2015

PENNA, P.M.M, et al. Biossegurança: uma revisão. Arquivos do Instituto de Biologia. v.77, n.3, p. 555-565, 2010. <http://www.biologico.sp.gov.br/docs/arq/v77_3/penna.pdf>. Acesso 05 de fev de 2015.

PEZZI, M.C.S.; LEITE, .J.L. Investigação em Central de Material e Esterelização utilizando a Teoria Fundamentada em Dados. Revista Brasileira de Enfermagem. v.63, n.3, 2010. Disponível em: http://www.scielo.br/scielo.php?pid=S0034$71672010000300007 \&$ script=sci_abstract\&tlng=pt $>$. Acesso: 02 de mar de 2015

RIBEIRO, R.P.; VIANNA, L.A.C. Uso dos Equipamentos de Proteção Individual entre trabalhadores das Centrais de Material e Esterilização. Ciência, Cuidado e Saúde. v.11, suplem, p.199-203, 2012. Disponível em: http://www.periodicos.uem.br/ojs/index.php/CiencCuidSaude/article/view/17076/pdf>. Acesso: 07 abril 2015.

SILVA et al. Acidente com material perfurocortante entre profissionais de enfermagem de um hospital universitário. Revista Gaúcha de Enfermagem. v. 31, n.4, p. 615-622, 2010. Disponível em:< http://www.scielo.br/pdf/rgenf/v31n4/a02v31n4.pdf>. Acesso: 29 de julho de 2015. 
Id on Line Revista Multidisciplinar e de Psicoloqia

Id on Line Multidisciplinary and Psycology Journal

SOCIEDADE BRASILEIRA DE ENFERMEIROS DE CENTRO CIRÚRGICO, RECUPERAÇÃO ANESTÉSICA E CENTRAL DE MATERIAL E ESTERILIZAÇÃO. Práticas recomendadas - SOBECC. 5.ed. São Paulo, 2009.

VALENÇA, C.N. et al. A produção científica sobre a saúde do trabalhador de enfermagem. Revista de pesquisa: cuidado é Fundamental. v.5, n.5, p.52-60, 2013. Disponível em:http://www.seer.unirio.br/index.php/cuidadofundamental/article/view/1615/pdf_987>. Acesso: 02 mar de 2015.

\section{Como citar este artigo (Formato ABNT):}

ALVES, Henrique E.; VALENÇA, C.N.; GUEDES, D.T.; REIS, Aline C.R.;SUGETTE, Juliana F.V.; CABRAL, Symara A.A.O. Riscos ocupacionais a que os trabalhadores da enfermagem referem estar expostos em central de material estéril. Id on Line Revista Multidisciplinar e de Psicologia, 2017, vol.11, n.37, p.1-12. ISSN: 1981-1179.

Recebido: 04.08.2017

Aceito: 05.08. 2017 